\title{
Developing an English Language Textbook Evaluative Checklist
}

\author{
Dr. Montasser Mohamed AbdelWahab \\ An Assistant Professor at Al Imam Muhammad Bin Saud Islamic University, College of Languages and \\ Translation \\ A TEFL Lecturer at Al M'aref Higher Institute for Languages and Translation
}

\begin{abstract}
In the selection of a new textbook, it is important to conduct an evaluation to ensure that it is suitable. Evaluation is widely acknowledged as a powerful means of improving the quality of education. There are three methods of evaluation that can be used for evaluating English Language Teaching (ELT) textbooks. An evaluative checklist is one of these methods that can be used to help select the most appropriate ELT textbooks for their learners. This paper presents an overall view of evaluating an ELT textbook with a focus on the instrument of a checklist. It tried to develop a valid, reliable and practical checklist. The paper refined checklists previously developed by different researchers. More specifically, the comments and suggestions given by a large number of TEFL professors helped the researcher improve the items of the checklist in reference to their clarity and inclusiveness. They were provided with a copy of the checklist. They were free to reword, delete or add items that they considered necessary. The findings are expected to be useful for English language teachers, ELT material developers and evaluators as well as curriculum developers. Further study is required to improve the instrument.
\end{abstract}

Keywords: Evaluation, textbook evaluation checklists

\section{Introduction}

Textbooks play a prominent role in the teaching /learning process as they are the primary agents of conveying knowledge to learners. Besides, one of the basic functions of textbooks is to make the existed knowledge available and apparent to the learners in a selected, easy and organized way. Hutchinson and Torres (1994) argue that any textbook has a very important and positive part to play in teaching and learning of English. They state that textbooks provide the necessary input into classroom lessons through different activities, readings and explanations. Thus, textbooks will always survive on the grounds that they meet certain needs. Richards (2001) states any learning program may have no impact if it does not have textbooks as they provide structure and a syllabus. Besides, the use of a textbook can guarantee that students in different classes will receive a similar content and therefore, can be evaluated in the same way. In other words, textbooks provide the standards in instruction. Moreover, they include a variety of learning resources such as workbooks, CDs, cassettes, and videos, etc., which make the learning environment interesting and enjoyable for learners. They do not only provide a framework for teachers in achieving the aims and objectives of the course, but also serve as a guide to the teacher when conducting lessons. The content of English language textbooks influences what teachers teach and learners learn.

In the selection of a new textbook, it is important to conduct an evaluation to ensure that it is suitable. Evaluation is widely acknowledged as a powerful means of improving the quality of education. Several researchers (Broadfoot et al. 1990, Stake et al. 1991, Gifford and O'Connor 1992) have drawn the attention of educational planners and administrators to the possibility of using changes in evaluation practices to reform the curriculum. Certain criteria must be considered in the evaluation. Since every teaching setting is unique in the sense that students have different backgrounds, abilities and needs, the criteria will inevitably vary. Other criteria such as teachers' perspectives as well as the syllabus should also be taken into account in the evaluation. The textbook evaluation criteria developed by the researcher for this study was based on a set of universal (but not theory-neutral) characteristics which not only correspond to the local needs, but also are flexible enough to be used worldwide with some modifications.

\section{Statement of the Problem}

It is true that many studies have dealt with evaluating English language textbooks, but these are still inadequate. Review of the available checklists indicated their validity, reliability or practicality problems (Mukundan \& Ahour, 2010). Therefore, there was a need for developing a checklist that had an inclusive account of the construct domain of the criteria, and accounts for consistency of the scores created by its items. For this purpose, the paper developed a textbook evaluation checklist on the basis of several well-established instruments. 


\section{Significance of the Study}

First, this study sought to develop an ELT textbook evaluative checklist based on current trends in ELT, curriculum design, and materials development. The use of the proposed checklist may have greater significance since it can reveal the strengths and weaknesses in the textbook, and determine whether or not the textbook is justified, or needs supplementation and/or modification. The study attempted to identify the linguistic errors or the factual mistakes, if any. It is also hoped that the study results would help in making some appropriate recommendations for the curriculum planners, educators and experts at educational institutes for further improving the quality of the English language textbook in general. This study may also provide guidance for any retrospective textbook evaluation or future revision of any English language textbook.

\section{Limitations of the Study}

The evaluative criteria used in this study were only some of the numerous possible sets of criteria against which an English Language textbook may be evaluated.

\section{Definition of Terms}

Evaluation is defined variously, depending on the subject matter, applied methodology or the application of its results. According to the Longman Dictionary of Contemporary English (2004), the most basic definition of evaluation is "the act of considering something to decide how useful or valuable it is". McGrath's (2001) basic explanation of textbook evaluation concerns the discovery of whether what you were looking for was there. When found, you then need to put a value on your findings. Evaluation implies judgment-making which therefore also means that evaluation is subjective. Although when evaluating, McGrath claims, that you might miss the unusual and the innovative ( $\mathrm{p} 22)$.

\section{Why evaluating textbooks}

The reasons for materials evaluation activities are also many and varied. One of the major reasons is the need to adopt new course books. Another reason as Cunningsworth (1995) emphasized is to identify particular strengths and weaknesses in textbooks already in use. Tomlinson (1996) also states that the process of materials evaluation can be seen as a way of developing our understanding of the ways in which it works and, in doing so, of contributing to both acquisition theory and pedagogic practices. It can also be seen as one way of carrying out action research.( p.238). Grant (1987, p.8) claimed (the) 'Perfect book does not exist', yet the aim was to find out the best possible one that will fit and be appropriate to a particular learner group. Sheldon (1988) suggested that textbooks did not only represent the visible heart of any ELT program, but also offer considerable advantages for both students and the teachers when they were being used in ESL/EFL classrooms. Cunnigsworth (1995) argued that textbooks were an effective resource for self-directed learning, an effective source for presentational material, a source of ideas and activities, a reference source for students, a syllabus where they reflected pre-determined learning objectives, and supported for less experienced teachers to gain confidence. In addition to that, Hycroft (1998) stated that one of the primary advantages of using textbooks was that they were psychologically essential for students since their progress and achievement could be measured concretely when they were used.

On the other hand, evaluation is universally accepted as an integral part of teaching and learning. It is one of the basic components of any curriculum and plays a pivotal role in determining what learners learn. ReaDickins and Germaine (1994) stated that "evaluation is an intrinsic part of teaching and learning" (p.4). Cunningsworth (1995: 7) suggested that the materials selected should reflect [the needs of the learners and the aims, methods and values of the teaching program. One other reason for textbook evaluation is that it can be very useful in teachers' development and professional growth. Ellis (1997) suggested that textbook evaluation helps teachers went beyond impressionistic assessments and it helped them to acquire useful, accurate, systematic and contextual insights into the overall nature of textbook material.

\section{Methods for Evaluating Textbooks}

There are three basic methods for evaluating textbooks. The first is called the impressionistic method and it involves analyzing a textbook on the basis of a general impression. The general impression would be gained by reading the blurb and the contents page and then skimming through the book to get a sense of organization, topics, layout and visuals. This method is not adequate in itself but could be combined with for example the second method, which is called the checklist method. This method is systematic in the way that the criteria on the list are checked off in a certain order. It is also very easy to compare different materials and it is not very time-consuming compared to other methods. The third method, the in-depth method, suggests a careful examination of representative features such as the design of one particular unit or exercise, or the treatment of particular language elements. An obvious disadvantage in this method is that the selected section might not be representative of the book as a whole. For the current study, the first and the second method were used. 
Ellis (1997) distinguished two types of materials evaluation, namely, predictive evaluation and retrospective evaluation. A predictive evaluation is designed to make a decision regarding what materials to use. Those who are required to carry out a predictive evaluation determine which materials are best suited to the determined purposes. Once the materials have been used, further evaluation may be conducted to find out whether the materials have worked out for the purposes determined and this type of evaluation is called retrospective evaluation. As can be understood from the aforementioned definitions, both predictive and retrospective evaluations aim at making the teaching/-learning environment more effective but the second type is only adopted for the present study.

Many different kinds of factors must be taken into account when selecting a textbook. McGrath (2001:19-21) listed a number of learner as well as teacher factors when selecting a textbook. As for learner factors, he concentrate on factors such as age range, proficiency level in the target language, reasons for studying the target language, sex distribution and so on. Following the learner factors is a list of learner needs, for example dialect, language-skill emphasis, language-system emphasis (grammar, vocabulary, phonology) and attention to mechanics (spelling, punctuation). Concerning the teacher factors, the focus was on language competence, methodological competence, awareness, and experience of teaching. Information about the institution and the specific program for which the material is intended is also important to consider. He mentioned for example level within the educational system (kindergarten, primary, secondary), class size, and aims of the program, syllabus and so on. In much the same way as McGrath (2001), Skierso (1991:432-434) listed a number of factors that need to be established before the evaluation process can start. Information is needed on the students, the teacher, the institution and so on. Just like McGrath, she also recommends a firstglance evaluation, although she refers to the process as survey, in which it is possible to eliminate the most unsuitable textbooks ( $\mathrm{p} 435$ ).

\section{Review of Related Literature}

Since evaluation is considered as an integral part in the educational process, many researchers have been very enthusiastic to conduct their studies in this field for the sake of the textbook improvement and modification. There is a vast literature on textbook evaluation. Therefore, the most relevant literature will be presented. While the theoretical literature review investigated the latest studies contributing to the theory of textbook evaluation, the empirical literature review briefed some related experimental studies on EFL/ESL textbook evaluation, with greater emphasis on those studies that used similar tools.

Williams (1983), Sheldon (1988), Brown (1995), and Cunningsworth (1995) all agreed, for instance, that evaluation checklists should have some criteria pertaining to the physical characteristics of textbooks such as layout, organizational, and logistical characteristics, methodology, aims, and approaches and the degree to which a set of materials is not only teachable, but also fits the needs of the individual teacher's approach as well as the organization's overall curriculum. Skierso (1991) divided materials that should be included in an evaluative checklist, into five sections: bibliographical data, aims and goals, subject matter, vocabulary and structures, and layout and physical makeup. Garinger (2001) stated that three content areas needed to be addressed when evaluating a textbook's content: teaching objectives, depth and breadth of material, and whether the textbook needs to be supplemented or not. This was consistent with the evaluation criteria suggested by Cunningsworth (1995) which were considered one of the most important works in EFL/ESL textbook evaluation. He proposed general criteria for textbook evaluation, which included 45 criteria in 8 categories: aims and approaches, design /organization, language content, study skills, topic, methodology, teacher's book, and practical considerations.

As part of his analytical framework Stradling (2001) constructed four main categories across which there were forty probing questions. Within each category Stradling offered questions that guided the process of developing the current EFL textbook evaluative checklist. Category one dealing with the evaluation of textbook content, included questions on coverage, sequencing and the curriculum, space allocation, the incorporation of multiple-perspectives, cultural and regional identity, and omissions. Category two, identifying the textbook's pedagogical value, included questions on students' prior skills and knowledge, on whether the textbook encourages memorization or skills development, on the use of charts and pictures, on the explication of historical concepts in the text, and on the facilitation of comparative thinking. The third category, identifying intrinsic qualities in history textbooks, included questions on assessing textbook pitch, on whether a text relies on reductionism, and on the possibilities for identifying author bias in texts. The last category dealt with extrinsic factors that may impact on the textbook. Questions to ascertain when the book first appeared on the market, the price and robustness of the textbook, whether the book is aimed at a specific group of students, and the extent to which the textbook will need to be complimented with alternative resources, are included in this category (pp. 258-263). Stradling provided an example of guidelines - criteria based on categories and questions - for analyzing textbooks. Perhaps Stradling's categories could be redefined and the questions appropriately reclustered. In addition, questions would need to be fine-tuned according to the specific focus of a given study. 
This may require the formulation of additional categories. Fetsko(1992. 132-133), for example, suggested a set of generic categories different to Stradling's including 'Readability', 'Format' and 'Quality of the Text' but his questions were more or less the same. Likewise, Crismore (1989:133) argued for the inclusion of categories that evaluate "the rhetorical form of textbooks" beyond merely the analysis of what information is included and omitted, in order to measure 'the way the content is presented'. Like Stradling, however, both Fetsko and Crismore referred to analytical criteria to be used by teachers and/or textbook selection committees. They were not writing for the benefit of the academic textbook researcher so their ideas must be adapted accordingly. Nevertheless, Stradling's categories and questions for evaluating textbooks represented an important and much needed example: a criterion from which to work from, a reference point from which to locate oneself, a beginning open to further discussion, just as Stradling intended.

Tomlinson (2001) offered a short summary of the history of materials development. He explained that the study of materials development was not given any real importance until the 1990s when books on this subject started to be published. A few books came out in the 1980s. He mentioned for example Cunningsworth (1984:69) and Sheldon (1987), but with these exceptions, materials development was treated as a sub-category of methodology. He claimed that research on the value of developing materials in different ways, as well as research on the effects of different kinds of materials, was still needed. Ma (2003) conducted an evaluation of the elementary English textbooks of the Nine-Year Integrated Curriculum. She used the ACTFL checklist as well as the Association of Language Testers in Europe as the framework to generate a set of textbook selecting criteria. Her findings showed that unequal distribution of the five Cs--Communication, Cultures, Connections, Comparisons and Communities was found, and that the textbooks emphasized communication design. Alternatively, in Pan's (2004) thesis, she reviewed the tentative versions of the junior high school English textbooks of the Nine-Year Integrated Curriculum. She inspected the distribution of the four language skills by counting the number of activities of each skill. First, she used Dubin and Olshtain's (1986) communicativeness scale as an instrument to investigate the five versions of junior high school English textbooks. Second, she distinguished the language skills and their integration into fifteen categories. Three raters are involved in the classification. Two randomly chosen lessons from each book were carefully reviewed by the three raters. She finally computed the degree of communicativeness of each book. She found that there was an unequal distribution of the four skills and the integrated skills.

Miekley (2005) provided a Textbook Evaluation Checklist that could be used to evaluate students' book and teachers' book. For the students' book he suggested four categories; content, vocabulary and grammar, exercises and activities, and attractiveness of the text and physical make-up. On the other hand he suggested four categories to be included in the process of evaluation of the teachers' book. They were general features, background information, methodological guidance, and supplementary exercises and materials. While this checklist is effective, additional questions should be added. For example, vocabulary may be a more important criterion to be included. Jahangard (2007) developed an evaluative checklist to evaluate four EFL textbooks which had been prescribed for use in Iranian high schools by the Ministry of Education. The merits and demerits of the textbooks are discussed in detail with reference to thirteen common features extracted from different material evaluation checklists. These criteria were explicit objectives, vocabulary explanation, educational approaches, review and test sections, visual materials, topics and tasks, clear instructions, layout, organized and graded content, authentic language, grammar presentation and practice, fluency practice in all four skills, and developing learning strategies. Mukundan (2011) presented a phase of an on-going project proposed out of the need for a valid, reliable and a practical checklist. The phase included a focus group study designed to further refine a checklist previously developed by those researchers. The study commenced in the form of an unstructured interview in which the participants brainstormed on the evaluative criteria that should be considered in evaluating ELT textbooks. This was followed by a structured interview in which the participants were provided with a copy of the checklist. They were free to reword, delete or add items that they consider necessary. As a result of their study, 14 items were added to the checklist while two were reworded. The present study adopted some of these items to be involved in the current developed checklist.

When selecting new English language textbooks to be used for teaching English language to students, it is very necessary to carefully examine that material to make sure that it is suitable for their particular institute setting. In this examination a number of different aspects were taken into consideration, for example the age and proficiency level of the students, what language factors that the students need to learn, the course syllabus and so on. This procedure of examining the material is called materials evaluation. This is the message that this study tried to prove and focused on using it.

\section{The Need for a Checklist}

It is a matter of fact that the method of selecting English language textbooks prescribed for students of different stages is unsatisfactory and away from being scientific. Three is a need for an evaluative checklist as a supporting way for choosing textbooks. Most advanced level English language textbooks, prescribed for 
students at different institutes, were not chosen by the careful application of objective evaluation criteria. It is obvious that the procedures followed are too often haphazard and that teaching materials are rarely chosen by the application of published evaluation checklists. A common method to obtain any new advanced depends on the basis of the subjective judgments or first impressions of those people. This situation is correctly described by Sheldon (1988:240), "checklists... have had little real influence on textbook evaluation".

It is suggested that this occurs because people in authority are often either unaware of the existence of checklists, cannot obtain them, do not want to make the effort of using them or are put off by their length and apparently complicated nature. These factors and time pressure to choose English language textbooks for students of different stages at any educational institutes quickly make this process inevitable. The textbook selected might also be evaluated continuously to consider whether the textbook is weak or strong, and whether that book is the best possible one for the class. The ongoing failure to create and use objective criteria when selecting English language textbooks at any educational institute is obvious.

One effective way of ensuring that the needs and wants of learners are given careful consideration when choosing English language textbooks is to apply a written checklist of appropriate selection criteria. The main purpose of the study is to motivate textbook selectors to critically examine the selection process they are currently using, and to offer those selectors an instrument to use for evaluating selected textbook. The checklist developed and presented in the present study could be considered to be appropriate in their particular teaching context. Such a checklist if used appropriately must be tailored to the needs and wants of the students of different stages at any educational institute. It is necessary to regard here that the checklist developed in this study is designed for educational institutes. A universally appropriate textbook could hardly exist, and neither could a universally appropriate English language evaluative checklist list. It is proposed that these previously mentioned points showed an urgent need for a flexible evaluative checklist which allows selection criteria to be agreed on beforehand.

\section{Methodology}

Through a comprehensive review of the relevant literature and studies, the paper sought to establish the prime criteria by which different aspects of any current EFL textbook would be analyzed and evaluated.

\section{Developing an English Language Textbook Evaluation Checklist}

A checklist is an instrument that helps practitioners in English Language Teaching evaluate language teaching materials, like textbooks. It allows a more sophisticated evaluation of the textbook in reference to a set of evaluative criteria. These checklists may be quantitative or qualitative. Quantitative scales have the merit of allowing an objective evaluation of a given textbook through Likert style rating scales (e.g., Skierso, 1991). Qualitative checklists, on the other hand, often use open-ended questions to elicit subjective information on the quality of course books (e.g., Richards, 2001). While qualitative checklists are capable of an in-depth evaluation of textbooks, quantitative checklists are more reliable instruments and are more convenient to work with. Many scholars offer checklists based on generalizable criteria. These detailed checklists use a variety of methods to evaluate how well a particular textbook measures certain standards. Farr and Tulley (cited in Chambliss, 1994) reviewed 70 checklists of English Language Textbooks and found that the number of criteria on the checklists ranged from 42 to 180 items.

The process of developing the current proposed checklist went through three phases;

\section{Phase one:}

1. Review of related literature and studies that tackled the process of developing EFL textbook evaluative checklists. The review of textbook evaluation checklists within four decades (1970-2000) by Mukundan and Ahour (2010) reveals that most of the checklists are qualitative (e.g., Rahimy, 2007; Driss, 2006; McDonough and Shaw, 2003; Rubdy, 2003; Garinger, 2002; Krug, 2002; McGrath, 2002; Garinger, 2001; Richards, 2001; Zabawa, 2001; Hemsley, 1997; Cunningsworth, 1995; Griffiths, 1995; Cunningsworth and Kusel, 1991; Harmer, 1991; Sheldon, 1988; Breen \& Candlin, 1987; Dougill, 1987; Hutchinson \& Waters, 1987; Matthews, 1985; Cunningsworth, 1984; Bruder, 1978; Haycraft , 1978; Robinett , 1978); than quantitative (e.g., Canado \& Esteban, 2005; Litz, 2005; Miekley, 2005; Harmer, 1998; Peacock, 1997; Ur, 1996; Skierso, 1991; Sheldon, 1988; Grant, 1987; Williams, 1983; Daoud \& Celce-Murcia, 1979; Tucker, 1978); or head words/outline format, i.e., those without rating scales or questions (Ansari \& Babaii, 2002; Littlejohn, 1998; Roberts, 1996; Brown, 1995). Most of these checklists are either too short or too long and some criteria in them are vague, so they do not thoroughly meet the requirements of a good and applicable instrument for evaluation purposes. The literature and studied reviewed guided the construction of the overall design of the current checklist and it was evident that textbook evaluation is necessary if proper materials were introduced and better methods of evaluation were followed. 


\section{Phase two:}

\section{Critical feedback survey}

It was used to as a way to gain insights into how several students and instructors view and look at ELT textbooks in general. The following steps were taken when conducting this survey:

1. Developing survey questions: A feedback survey is usually lengthy. Creating the right type of questions is important. Questions or statements are rated on a 5-point scale. The critical feedback survey was a pen-andpaper survey designed to collect specific data to evaluate the checklist based on Stufflebeam's (2000) eight criteria for evaluating a checklist including applicability to the full range of intended uses ,clarity, comprehensiveness, concreteness, ease of use, fairness, parsimony, and pertinence to the content area.

2. Administering the survey: Since the survey takes a minimum of one hour to complete, students and instructors were given enough time to do so. Online administration was a convenient way of administering the survey. This makes it easier to gather truthful answers on the survey.

3. Collecting and analyzing the data: In a pen \& paper administration, the results were collected and entered into a program. In an online administration, the results were automatically compiled into a data analysis program. The simplest analysis that is done on the responses was an average of the ratings. More complex analyses would be item and factor analyses. Depending on the dimension, the highest and lowest rated statements can be identified for further analyses.

Opinions were gathered and the results were helpful in designing the first version of the checklist. It pinpointed the main points that should be included in the checklist. Their responses were highly considered and useful. It helped the researcher create and develop the four main categories included in the main checklist. It also played a vital role in the process of selecting a large number of the subcategories.

\section{Semi-structured interviews and Written comments}

The interviews 'section was devoted to ask the expert panel members four open-ended questions regarding the strengths and weaknesses of the checklist, items missing from the checklist, and recommendations for improving the checklist. The entire written response for the particular question made up the context unit. The small sample size of expert panel participants allowed for the analysis of all written comments made on the survey form. As a result of this phase of the study, some items (7) were added to the checklist, while others (3) were revised. The participants were free to share their views on the important evaluative criteria to be taken into account in evaluating textbooks are reported in this section.

\section{a) The Added Items}

The researcher examined the transcripts, and in reference to the participants ${ }^{\text {ee }}$ statements, a number of criteria was added to the checklist. These added items were:

1. Binding is strong enough.

2. The three Ps of culture are represented in the content.

3. Printing used is good.

4. Students are encouraged to bring real objects in class to illustrate some points of learning.

5. The topics of the content cope with the criteria of the students' culture

6. The textbook helps teachers exploit the activities to meet the 7students' expectations.

7. Grammar lessons are often derived from the listening or reading passages

\section{The Deleted Items}

Based on the experts' opinions, some items were deleted. They were;

1. The item, "The paper is of good quality" was deleted as it was already included in the following item," The paper used for the textbooks is of good quality".

2. The following item, "Teachers are asked to bring in extra objects to be teaching aids for them in the process of learning" was deleted as it was considered irrelevant.

\section{The Merged Items}

1. The three following items; "The subject and content of the textbook is interesting", "The subject and content of the textbook is challenging", and "The subject and content of the textbook is motivating" were merged to be one item," The subject and content of the textbook is interesting, challenging, and motivating".

2. The same issue applied to the following three items; "Many of the reading passages are up-to-date", "Many of the reading passages are interesting", and "Many of the reading passages are meaningful". They were included in one item, "Many of the reading passages are up-to-date, interesting, and meaningful". 
3. The items included in the sub-category, "visuals", three items were merged together to be one item. These three items were "The Visuals are well produced", "The Visuals are varied" and "The Visuals are attractive".

4. The three items," The exercises are adequate", "The exercises are purposeful" and "The exercises are interesting." were merged into one item," The exercises are adequate, purposeful, and interesting".

\section{The Modified Items}

1. The item, "The textbook has appropriate listening tasks." was modified to be "The textbook has appropriate listening tasks with well-defined goals".

2. The item, "Activities are developed to encourage student-teacher oral communication." was modified to be , "Activities are developed to encourage student-student and student-teacher oral communication."

3. The item," The titles are written clearly and appropriately" was modified to be" The titles and sub-heading titles are written clearly and appropriately.

4. The following item, "Every unit is given an appropriate title." was modified to be, "Every unit and lesson is given an appropriate title."

5. The item, "The textbook helps teachers cater for mixed- ability students" was modified to be "The textbook helps teachers cater for mixed- ability students and classes of different sizes.".

6. The following item, "The textbook provides a variety of meaningful exercises and activities to practice language items." was modified to be "The textbook provides a variety of meaningful and mechanical exercises and activities to practice language items and skills."

7. The item, "The grammar points introduced in motivating and realistic contexts." was modified to be, "The grammar points and vocabulary items are introduced in motivating and realistic contexts."

On the other hand, there were issues raised by the participants that were disregarded. For instance, it was suggested to add items that addressed promoting autonomous and discovery learning. However, the developers assumed such matters relate to classroom procedures that are often controlled by the teacher rather than by the textbook. Therefore, they would be more relevant for teacher observation sheets.

\section{Phase Three:}

\section{A Single Case Study}

One effective way of ensuring that the checklist developed in this current study is effective and suitable to be used in evaluating ELT textbooks is to apply it in practical evaluation of an ELT textbook sample. The main purpose of this application was to examine the validity of the current proposed checklist to critically examine the selection process the authors were currently using, and to offer those selectors an instrument to use for evaluating selected textbook. The checklist developed and presented in the present study could be considered to be appropriate in their particular teaching context. Such a checklist was used appropriately to evaluate three English Language textbooks; "Move Ahead 3"( Ellis, Wilson \& Taylor:2001) "Touch Stone"(McCarthy, Mecarten and Sandford:2010), and Step Forward, Step by Step, Lesson Plans (Adelson-Godstein:2007). The first book was evaluated by the researcher while the second and the third books were evaluated by other researchers. The evaluative checklist proved to be reliable and valid as a comprehensive tool of evaluation. Its practicality and clarity were assured through the process of evaluating the three ELT textbooks stated previously..

\section{The Final version of the Checklist}

The checklist took elements from the checklists of Soori, Kafipour and Soury, 2011; Mukundan , Nimehchisalem and Hajimohammadi 2011; Tok, 2010 ; Bataineih, 2009; Alamri, 2008 ; Rahimy, 2007; Driss, 2006; Miekley, 2005 ; Xu, 2004 ; Rubdy, 2003; Ansary and Babaii, 2002; Garinger, 2002; Richards, 2001; Zabawa, 2001; Harmer, 1998; Chambers, 1997; Cunningsworth, 1995; Roberts 1990; Sheldon 1988; Candlin, 1987; Matthews,1985; Cunningsworth,1984; Williams, 1983, R. Williams,1981 and adapted them, with the addition of new items and a new scoring system. The hope with this flexible checklist was that the process of selecting an English language textbook must be based on the needs and wants of the learners as well as the needs and wants of the educational institute.

Based on the previously mentioned review of literature, the paper developed a 140- item evaluative checklist. The items of the evaluative checklist were grouped under four domains:

1) Physical and utilitarian attributes (25 items);

2) Efficient outlay of objectives and supplementary materials (33 items);

3) learning-teaching content ( 28 items), and

4) Language Skills (54 items). 
The first category was further divided into three sub-categories;

1) General appearance ( 9 items)

2) Layout and design (12 items); and

3) Visuals (4 items).

The criteria in the second category, on the other hand, included the following;

1) Book objectives (10 items);

2) Teaching aids (9 items); and

3) Teaching methods (14 items).

The criteria in the third category included the following sub-categories;

1) Subject and content (9 items);

2) Exercises (10 items) and;

3) social and cultural contexts ( 9 items).

The fourth category focused on seven sub-categories;

1) Listening (7 items);

2) Speaking (6 items);

3) Reading (6 items);

4) Writing (8 items);

5) Grammar (11 items);

6) Vocabulary (11 items); and

7) Pronunciation (5 items).

\section{Validity of the Instrument}

As it was shown previously two separate investigations were conducted to empirically validate the checklist. The methods applied to this study included qualitative and quantitative survey research and case study research. The use of a mixed method approach was deemed important to achieve the primary benefits of development and expansion of the checklist (Greene,Caracelli,\&Graham,1989). The use of an expert panel to provide critical feedback served to facilitate the development and refinement of the checklist application in the second investigation. In addition, the expert panel was considered an integral design element to demonstrate content relevance and representativeness along with the substantive and consequential aspects of validity. The case study research method facilitated learning about the practicality of the checklist in its contextual setting thereby extending the scope and breadth of the validity study (Yin,2009).

\section{Reliability of the Instrument}

Several approaches were used to minimize measurement error in this study. The first was the use of a pilot test of the critical feedback survey to assess the clarity of directions, question wording, and rating procedure, among other elements (Fink,2003). The use of a systematic approach for the expert panel members to apply the ratings also contributed towards minimizing measurement error. Internal consistency of the survey instrument was estimated using Cronbach's co efficient alpha. In this particular study, coefficient alpha ranged from.78 to.79 suggesting a high estimate of reliability based on the mean inter-item correlation. What is more, the use of expert panel members with diverse backgrounds suggests potential stability over time (Yin,2009). The following table determined the reliability of the checklist,

Table (1):Alpha Formula of Instrument Reliability

\begin{tabular}{|l|l|}
\hline Domains & Reliability \\
\hline Physical and utilitarian attributes & 0.78 \\
\hline $\begin{array}{l}\text { Efficient outlay of objectives and supplementary } \\
\text { materials }\end{array}$ & 0.71 \\
\hline learning-teaching content & 0.78 \\
\hline Language Skills & 0.79 \\
\hline Total score & 0.87 \\
\hline
\end{tabular}

\section{Data Collection}

The newly developed checklist was used to collect as many types of data as possible. This checklist was designed to produce a score for the textbook evaluated. There were 140 item on the checklist, with two 
points possible for each item. The criteria were numerically rated on a scale from 0 to 2 in the blank space of the score column as follows:
Poor $=0$
Satisfactory $=1$
Good $=2$
(It goes up to 64\%.)
(It starts with $65 \%$ and goes up to $74 \%$.)
(It starts with $75 \%$.)

First, an evaluation checklist with two columns was designed. The universal features of EFL textbooks tailored and adapted to the needs of the learners appeared in the first column on the form. A merit score consisting of numbers 0 to 2 appeared in the second column on the checklist. A comparative weight was assigned to the relative realization of each actual criterion in the textbook under scrutiny: a perfect match between the ideal defined criterion and its actual realization in the textbook receiving two, a total lack a score of zero, and any inadequate match a score of one. Finally, the numbers in the merit score column after each criterion were represented on charts.

The first version of the checklist was distributed on the jury who gave their opinions concerning each item. The validity of the checklist was ensured as the jury involved a number of experts who are familiar with the research context. The reason for using such a way was that it could provide a practical method to validate an instrument in the process of its development before it is used (Weir, 1993). Experts" views on the construct and wording of the items would enable the researcher to realize certain crucial issues that had been neglected in the development of the checklist. Procedures of data collection and analysis went simultaneously and a selected EFL textbook was explored thoroughly with a particular focus on the proposed current checklist criteria under four main categories; Physical and utilitarian attributes, efficient outlay of objectives and supplementary materials, learning-teaching content, and language skills with sixteen subcategories: general appearance, layout and design, illustrations, book objectives, teaching aids, teaching methods, subject and content, exercises, social and cultural contexts, listening, speaking, reading, writing, grammar, vocabulary, and pronunciation.

\section{Conclusion}

According to the findings of this paper it would not be an overstatement to say that the quality of the curriculum reform basically depends on a good process of evaluation. Also, any new textbook can be expanded to include more information about the ideals such as constructivist learning, multiple intelligences theory, taskbased learning so and so forth. More importantly, more games, activities, tasks together with their classroom implementations should be added to the textbook.

There are several limitations to these findings, however. First, different self-report instruments, structured interviews, diary keeping studies, as well as observations can reveal more specific data about the English language textbook evaluative checklist as well as the effectiveness of its implementation. The nature of the instrument, therefore, limits the possibility of a more in-depth analysis than the one presented in this stud. Despite its limitations, however, this study makes contributions to the existing literature on textbook evaluation in general and English Language Teaching textbook in specific. It also mirrors results from previous research studies by showing the existence of similarities and differences in the way of evaluation. Therefore, it is important that all individuals involved at all levels, from policy makers to administrators, material designers, curriculum developers, textbook writers, and teachers, consider the importance of their decisions and make wise judgment at right time, and strive to effectively match textbooks with the identified needs of the learners.

\section{Recommendations}

In the light of the review of the literature regarding good quality textbook and the application of the evaluation checklist, the researcher recommended the following criteria to be taken into account when selecting and evaluating an English language textbook:

1) Physical and utilitarian attributes;

2) Efficient outlay of objectives and supplementary materials ;

3) learning-teaching content; and

4) Language Skills

On the basis of the above conclusions, and to achieve the avowed goals of this study the researcher puts forward the following recommendations. It is hoped that the process of selecting the content of EFL textbooks could be improved by following these recommendations:

1- Textbooks should be revised from time to time to make sure they are free from spelling, grammatical and lexical mistakes.

2- An appropriate plan should be organized in which the roles of textbook developers, teachers, students, and educational managers at a specific stage of learning and teaching are stated clearly. 
3- In revising the textbooks, good qualities of the textbooks should be retained and the shortcomings should be eliminated or at least reduced.

4- Teachers and supervisors should be consulted when selecting the material, and they should participate in making any modifications or improvements concerning the textbooks.

5- Finally, materials development is by now an area of specialization with abundant literature; therefore, textbook writers are required to appreciate and use principles of materials development in the process of writing and revising books.

\section{Recommendations for Further Studies}

1- Using the suggested designed evaluative checklist to evaluate English language textbooks.

\section{Reference}

[1]. Adelson-Godstein, Jayne (2007). Step Forward, Step by Step, Lesson Planning, Oxford University Press

[2]. Allwright, R L. (1981).What do we want teaching materials for? ELT Journal 36/1, pp. 5-18 [Electronic version].

[3]. Al-Saif, Abdullah. (2005). An evaluation of the TEFL textbook for the 6th elementary class in Saudi Arabia. Unpublished MA thesis, 78 pages. Essex University, UK.

[4]. Ansary, H. \& Babaii, E.(2002). Universal characteristics of EFL/ESL textbooks: A step towards systematic textbook evaluation. The Internet TESL Journal, Vol. 8 (2). Retrieved November 10, 2005, from http://iteslj.org/Articles/Ansary-Textbooks/

[5]. Breen, M. \& Candlin, C. (1987). What materials? A consumer"es and designere"s guide. In L. E. Shelden (ed.). ELT textbook and materials: Problems in evaluation and development. ELT Documents 126. (pp. 13-28) Oxford: Modern English Publications in association with The British Council.

[6]. Broadfoot, P., Murphy, R. and Torrance, H. (eds) (1990) Changing Educational Assessment: International Perspectives and Trends (London: Routledge).

[7]. Brown, J. D. (1995). The elements of language curriculum. New York: Heinle \& Heinle Publishers.

[8]. Bruder, M. N. (1978). Evaluation of foreign language textbooks: A simplified procedure. In H. S. Madsen and J. D. Bowen. Adaptation in language teaching. Appendix 2 (pp. 209-218). Rowley, Mass: Newbury.

[9]. Canado, M.L.P. \& Almagro Esteban, A. (2005). Authenticity in the teaching of ESP: An evaluation proposal. Scripta Manent 1(1), 35-43. Retrieved from http://www.sdutsj.edus.si/ScriptaManent/ 2005_1/Perez_Almagro.pdf

[10]. Chambers, F. (1997). 'Seeking Consensus in Textbook Evaluation'. ELT Journal. Volume 51/1.

[11]. Chambliss, Marilyn J. (1994). Evaluating the quality of textbooks for diverse learners. Remedial \& Special Education, 15 (6), p 348. Retrieved November 10, 2005, from http://search.epnet.com/login.aspx? direct=true \&db=aph\&an=9411151353

[12]. Crismore, A. (1989) 'Rhetorical Form, Selection and the Use of Textbooks' in Suzanne de Castell et al. (ed) Language, Authority and Criticism - Readings on the School Textbook London, New York and Philadelphia, The Falmer Press.

[13]. Cunningsworth, A. (1984). Evaluating and selecting EFL teaching materials. London: Heinemann Educational Books.

[14]. Cunningsworth, A., \& Kusel, P. (1991). Evaluating teachers"e guides. ELT Journal 45(2): 128-139.

[15]. Cunningsworth, A (1995). Choosing your Textbook. London: Macmillan: Heinemann

[16]. Daoud, A. M. \& Celce-Murcia, M. (1979). Selecting and evaluating a textbook. In M. Celce-Murcia and L. McIntosh, eds. TESL or TEFLPp: 302-307. New York: News bury House. ELT documents 126.Pp. 29-36, Oxford: Modern English Publications in Associations with the British Council.

[17]. Dougill, J. (1987). Not so Obvious. In L. E. Shelden (ed.). ELT textbook and materials: Problems in evaluation and development

[18]. Driss, L. (2006). Systematic Textbooks Supplementation (knowing when to supplement and what to add). US Department of State, Ministry of Education, Morocco, University of Delaware, English Language Institute. Retrieved from http://www.udel.edu/eli/2006P4L/driss.pdf

[19]. Dubin, Fraida, and Elite Olshtain. 1986. Course design: Developing Programs and Materials for Language Learning. Cambridge: Cambridge University Press.

[20]. Ellis, Printha; Wilson, Ken and Taylor, James (2002). Move Ahead. Macmillan Publishers Limited, Cambridge UK

[21]. Ellis, Rod. (1997). The empirical evaluation of language teaching materials. ELT Journal, 51(1), pp. 36-42 [Electronic version].

[22]. Ellis, Wilson \& Taylor (2001). Move Ahead 3 Student's Book. Macmillan Education.

[23]. Fetsko, W. (1992) 'Approaching Textbook Selection Systematically' in Herlihy, J.G. (ed) The Textbook Controversy - Issues, Aspects, Perspective New Jersey, Norwood.

[24]. Fink,A.(2003). The survey handbook(2nded.).ThousandOaks,CA:Sage.

[25]. Fredriksson, C. and Olsson, R.(2006). English Textbook Evaluation An Investigation into Criteria for Selecting English Textbooks. http://www.britannica.com

[26]. Garinger, D. (2001). Textbook evaluation. TEFL Web Journal. Retrieved from http://www.teflweb-j.org/v1n1/garinger.html

[27]. Garinger, D. (2002). Textbook selection for the ESL classroom. Center for Applied Linguistics Digest. Retrieved from http://www.cal.org/resources/Digest /0210 garinger.html

[28]. Giffodr, B. R. and O'Connor, M. C. (eds) (1992) Future Assessments: Changing Views of Aptitude, Achievement and Instruction (Boston: Kluwer).

[29]. Grant, N. (1987). Making the most of your textbook. London: Longman Inc.

[30]. Griffiths, C. (1995). Evaluating materials for teaching English to adult speakers of other languages. Forum 33(3): 50. Retrieved from http://forum.state.gov/vols/vol33/ no3/p50.htm

[31]. Garinger, Dawn. (2001). Textbook evaluation. Retrieved December12, 2005, from http://www.teflweb-j.org/v1n1/garinger.html

[32]. Greene,J.C.,Caracelli,V.J.,\&Graham,W.F.(1989).Toward A Conceptual Framework for Mixed-Method Evaluation Designs. Educational Evaluation and Policy Analysis, 11, 255-274.

[33]. Harmer, J. (1991). The practice of English language teaching.Harlow, Essex : Longman

[34]. Harmer, J. (1998). How to teach English. Harlow, Essex: Addison Wesley Longman.

[35]. Haycraft, J. (1978). An introduction to English language teaching. London: Longman.

[36]. Hemsley, M. (1997). The evaluation of teachers ${ }^{e c}$ guides-design and application. ELTED 3(1): 72-83. 
[37]. Hutchinson, T. \& Waters, A. (1987). English for specific purposes: A learning-centered approach. Cambridge: Cambridge University Press.

[38]. Hutchinson, T and \&Torres, E (1994). The Textbook as an Agent of Change. ELT Journal 48,4

[39]. Hycroft J (1998). An Introduction To English Language Teaching Longman.

[40]. Jahangard, Ali (2007). Evaluation of the EFL materials taught at Iranian high schools. The Asian EFL Journal, 9 (2), $130-150$.

[41]. Krug, K. (2002). Some points to ponder in textbook evaluation. Retrieved from http://www.kutztown.edu/library/ materials /textbookeval.htm

[42]. Littlejohn, A. (1998). The analysis of language teaching materials: Inside the Trojan horse. In B. Tomlinson (ed.) Materials development in language teaching. Cambridge: Cambridge University Press, 190-216.

[43]. Litz, D.R.A. (2005). Textbook Evaluation and ELT Management: A South Korean Case Study. Asian EFL Journal. Retrieved from http://www.asian-efl-journal.com/Litz_thesis.pdf

[44]. Longman dictionary of contemporary English (4th ed.). (2003). Harlow, England: Longman

[45]. Ma, Ling-Ling. 2003. Evaluation of current English textbooks for the elementary school: A study of English textbooks designed for the 1st-9th grades curriculum alignment in Taiwan. Unpublished master's thesis, Fu-Jen Catholic University, Taiwan, R.O.C.

[46]. Matthews, A. (1985). Choosing the best available textbook. In A. Matthews, M. Spratt, and L. Dangerfield (eds.). At the chalkface. (pp. 202-206). London: Edward Arnold.

[47]. McCarthy,Michael, Mecarten, Jonne, and Sanford, Helen (2010). Touch Stone 3. Cambridge- Obeiko.

[48]. McDonough, J. \& C. Shaw. (1993). Materials and Methods in ELT. Oxford: Blackwell.

[49]. McDonough,J. \& Shaw, C. (2003). Materials and methods in ELT: A teacher's guide. (2nd Ed.). Malden, MA: Blackwell Publishing Ltd.

[50]. McGrath, Ian. (2001). Materials Evaluation and Design for Language Teaching. Edinburgh: Edinburgh University Press, 2001.

[51]. Miekley, J. (2005). ESL textbook evaluation checklist. The Reading Matrix, 5, No. 2, September 2005. Retrieved from: http://www.readingmatrix.com/reading projects/

[52]. Mukundan, J. \& Ahour, T. (2010). A review of textbook evaluation checklists across four decades (1970-2008). In Tomlinson, B., Masuhara, H. (Eds.). Research for materials development in language learning: Evidence for best practice (pp. 336-352). London: Continuum.

[53]. Mukundan,J. ,Hajimohammadi, R. and Nimehchisalem,V. (2011). Developing An English Language Textbook Evaluation Checklist. Contemporary Issues In Education Research - June 2011. Volume 4, Number 6

[54]. Pan, Pei-hsuan. 2004. Evaluation of learning activities in junior high school English textbooks for Nine-Year Integrated Curriculum. Unpublished master's thesis, National Normal University, Taiwan, R.O.C.

[55]. Peacock, M. (1997). Choosing the right book for your class. Retrieved from http: //www.sx.ac.uk/linguistics/pgr/egspll/volume1/ PDFs/PEACOCK1.pdf

[56]. Rahimy, R. (2007). A coursebook evaluation. ESP World, 6, Issue 2(15). Retrieved from http://www.esp-world.info/contents.htm

[57]. Rea- Dicckens PP, Germaine K (1994). Evaluation In Canadlin and Widdowson (ed.), Oxford University Press.

[58]. Richards, J. C. (2001). Curriculum development in language teaching. Cambridge: Cambridge University Press.

[59]. Roberts, J. T. (1996). Demystifying materials evaluation. System, 24(3): 375-389.

[60]. Robinett, W. (1978). Teaching English to speakers of other languages: Substance and technique. Minneapolis: University of Minnesota Press.

[61]. Rubdy, R. (2003). Selection of materials. In B. Tomlinson. Developing materials for language teaching. (pp. 37-57). London: Continuum.

[62]. Sheldon, LE. (1987) Introduction in ELT Textbooks and Materials: Problems in Evaluation and Development

[63]. Sheldon, L. E. (1988) Evaluating ELT textbooks and materials. ELT Journal, 42(4):237-246.

[64]. Skierso, Alexandra. (1991). Textbook Selection and Evaluation. In M. Celce-Murcia (Ed.), Teaching English as a second or foreign language, 432-453. Boston: Heinle and Heinle Publishers.

[65]. Soori ,A.; Kafipour, R.; and Soury M. (2011). EFL Textbook Evaluation and Graphic Representation. European Journal of Social Sciences. ISSN 1450-2267 Vol.26 No.3 (2011), pp. 481-493 EuroJournals Publishing, Inc. 2011, http://www. European journal of social sciences.com

[66]. Stake, R. E., Hood, S. and O’Sullivan, R. G. (eds) (1991) Advances in Program Evaluation: A Research Annual: Using Assessment Policy to Reform Education, Part A, Vol. 1(Greenwich, CT: JAI Press).

[67]. Stradling, R. (2001) Teaching 20th - century European history Strasbourg, Council of Europe Publishing.

[68]. Tok, Hidayet (2010). TEFL textbook evaluation: From teachers' perspectives. Educational Research and Review Vol. 5 (9), pp. 508-517, September 2010. ISSN 1990-3839 @ 2010 Academic Journals. http://www.academicjournals.org/ERR2

[69]. Tomlinson, B. (Ed.). (1996). Materials development in language teaching. Cambridge: Cambridge University Press.

[70]. Tomlinson, B. et al. (2001). ELT Courses for Adults. ELT Journal, 55(1) 80-101.

[71]. Tucker, C. A. (1978). Evaluating beginning textbooks. In H. S. Madsen and J. D. Bowen. Adaptation in language teaching. Appendix 3 (pp. 219-237). Rowley, Mass: Newbury.

[72]. Ur, P. (1996). A course in language teaching: Practice and theory. Cambridge: Cambridge University Press.

[73]. Peacock, M. (1997). Choosing the right book for your class. Retrieved from http: //www.sx.ac.uk/linguistics/pgr/egspl1/volume1/ PDFs/PEACOCK1.pdf

[74]. Rahimy, R. (2007). A coursebook evaluation. ESP World, 6, Issue 2(15). Retrieved from http://www.esp-world.info/contents.htm

[75]. Rea- Dicckens PP, Germaine K (1994). Evaluation In Canadlin and Widdowson (ed.), Oxford University Press.

[76]. Richards, J. C. (2001). Curriculum development in language teaching. Cambridge: Cambridge University Press.

[77]. Roberts, J. T. (1996). Demystifying materials evaluation. System, 24(3): 375-389.

[78]. Robinett, W. (1978). Teaching English to speakers of other languages: Substance and technique. Minneapolis: University of Minnesota Press.

[79]. Rubdy, R. (2003). Selection of materials. In B. Tomlinson. Developing materials for language teaching. (pp. 37-57). London: Continuum.

[80]. Sheldon, LE. (1987) Introduction in ELT Textbooks and Materials: Problems in Evaluation and Development

[81]. Sheldon, L. E. (1988) Evaluating ELT textbooks and materials. ELT Journal, 42(4):237-246.

[82]. Skierso, Alexandra. (1991). Textbook Selection and Evaluation. In M. Celce-Murcia (Ed.), Teaching English as a second or foreign language, 432-453. Boston: Heinle and Heinle Publishers.

[83]. Soori ,A.; Kafipour, R.; and Soury M. (2011). EFL Textbook Evaluation and Graphic Representation. European Journal of Social Sciences. ISSN 1450-2267 Vol.26 No.3 (2011), pp. 481-493 EuroJournals Publishing, Inc. 2011, http://www. European journal of social sciences.com 
[84]. Stake, R. E., Hood, S. and O’Sullivan, R. G. (eds) (1991) Advances in Program Evaluation: A Research Annual: Using Assessment Policy to Reform Education, Part A, Vol. 1(Greenwich, CT: JAI Press).

[85]. Stradling, R. (2001) Teaching 20th - century European history Strasbourg, Council of Europe Publishing.

[86]. Stufflebeam, DL (2000) The Methodology of Metaevaluation as Reflected in Metaevaluations by the Western Michigan University Evaluation Center, Journal of Personnel Evaluation in Education, Vol.14 (1): 95-125

[87]. Tok, Hidayet (2010). TEFL textbook evaluation: From teachers' perspectives. Educational Research and Review Vol. 5 (9), pp. 508-517, September 2010. ISSN 1990-3839 (C) 2010 Academic Journals. http://www.academicjournals.org/ERR2

[88]. Tomlinson, B. (Ed.). (1996). Materials development in language teaching. Cambridge: Cambridge University Press.

[89]. Tomlinson, B. et al. (2001). ELT Courses for Adults. ELT Journal, 55(1) 80-101.

[90]. Tucker, C. A. (1978). Evaluating beginning textbooks. In H. S. Madsen and J. D. Bowen. Adaptation in language teaching. Appendix 3 (pp. 219-237). Rowley, Mass: Newbury.

[91]. Ur, P. (1996). A course in language teaching: Practice and theory. Cambridge: Cambridge University Press.

[92]. Williams, D. 1983. Developing criteria for textbook evaluation. ELT Journal, 37 (3), 251 -255 [Electronic version].

[93]. Williams, M. \& Burden, R.L. (1994). The role of evaluation in ELT project design. In English Language Teaching Journal,48/1, 22-27.

[94]. Williams, R. (1981) A procedure for ESP textbook analysis and evaluation on teacher education courses. The ESP Journal, (2), $155-162$

[95]. Zabawa, J. (2001). Criteria for FCE textbook evaluation: an attempt at questionnaire formulation. Retrieved from: http://www.univ.rzeszow.pl/fil_ang/wsar2/sar_v2_17.pdf

[96]. Williams, D. 1983. Developing criteria for textbook evaluation. ELT Journal, 37 (3), 251-255 [Electronic version].

[97]. Williams, M. \& Burden, R.L. (1994). The role of evaluation in ELT project design. In English Language Teaching Journal,48/1, $22-27$.

[98]. Williams, R. (1981) A procedure for ESP textbook analysis and evaluation on teacher education courses. The ESP Journal, (2), 155-162

[99]. Yin,R.K.(2009).Casestudyresearch:Designandmethods(4thed.).ThousandOaks,CA: Sage.

[100]. Zabawa, J. (2001). Criteria for FCE textbook evaluation: an attempt at questionnaire formulation. Retrieved from: http://www.univ.rzeszow.pl/fil_ang/wsar2/sar_v2 17.pdf

A Final Version of the Evaluative Checklist

\begin{tabular}{|c|c|c|c|}
\hline Items of Evaluation & Good & Satisfactory & Poor \\
\hline \multicolumn{4}{|l|}{$\begin{array}{l}\text { I. Physical and utilitarian attributes } \\
\text { A- General Appearance } \\
1 \text { The outside cover is informative and attractive. }\end{array}$} \\
\hline \multicolumn{4}{|l|}{2 The font size and type used in the book are appropriate. } \\
\hline \multicolumn{4}{|l|}{ 3. The paper used for the textbooks is of good quality } \\
\hline \multicolumn{4}{|l|}{ 4. Binding is strong enough. } \\
\hline \multicolumn{4}{|l|}{ 5. Printing used is good. } \\
\hline \multicolumn{4}{|l|}{ 6. There is enough white space to achieve clarity. } \\
\hline \multicolumn{4}{|l|}{$\begin{array}{l}\text { 7. The titles and sub-heading titles are written clearly and } \\
\text { appropriately }\end{array}$} \\
\hline \multicolumn{4}{|l|}{ 8. Its size is appropriate } \\
\hline \multicolumn{4}{|l|}{$\begin{array}{l}\text { 9. The textbook has sufficient number of pictures to make the } \\
\text { situation more life-like. }\end{array}$} \\
\hline \multicolumn{4}{|l|}{$\begin{array}{l}\text { B- Layout and design } \\
1 \text { There is a variety of design to achieve impact. }\end{array}$} \\
\hline \multicolumn{4}{|l|}{$\begin{array}{l}\text { 2. There is consistency in the use of headings, icons, labels, } \\
\text { italics, etc. }\end{array}$} \\
\hline \multicolumn{4}{|l|}{$\begin{array}{l}\text { 3. The textbook includes a detailed overview of the functions } \\
\text { and structures that will be taught in each unit. }\end{array}$} \\
\hline \multicolumn{4}{|l|}{$\begin{array}{l}\text { 4. The textbook includes a detailed overview of vocabulary that } \\
\text { will be taught in each unit. }\end{array}$} \\
\hline \multicolumn{4}{|l|}{ 5. The textbook has a complete and detailed table of contents. } \\
\hline \multicolumn{4}{|l|}{ 6. Every unit and lesson is given an appropriate title. } \\
\hline \multicolumn{4}{|l|}{ 7. The textbook has a complete bibliography. } \\
\hline \multicolumn{4}{|l|}{ 8. The textbook is organized logically and effectively. } \\
\hline \multicolumn{4}{|l|}{ 9. An adequate vocabulary list or glossary is included. } \\
\hline \multicolumn{4}{|l|}{ 10. Adequate review sections and exercises are included. } \\
\hline \multicolumn{4}{|l|}{ 11. The textbook is free of mistakes } \\
\hline \multicolumn{4}{|l|}{ 12. The textbook is durable. } \\
\hline \multicolumn{4}{|l|}{$\begin{array}{l}\text { C-Visuals } \\
\text { 1. The Visuals are well produced, varied and attractive }\end{array}$} \\
\hline \multicolumn{4}{|l|}{ 2. The Visuals stimulate students to be creative. } \\
\hline \multicolumn{4}{|l|}{ 3. The Visuals are functional. } \\
\hline 4. The Visuals are compatible with students' own culture. & & & \\
\hline
\end{tabular}


2. Efficient outlay of objectives and supplementary materials.

a. Book Objectives

1. The textbook fulfills the general objectives of teaching

English language at the specified educational institute.

2. The objectives are related to the learners' needs and interests

3 . The objectives are specified explicitly in the textbook .

4. The objectives are measurable

5. The objectives are relevant to the students' local culture.

6. The objectives make a balance between the four main skills, listening, speaking, reading and writing

7. The objectives help the teacher to choose the right aids and the best methods of teaching

8. The six levels of Bloom's Taxonomy are dominant in the textbook.

9. The content underlines the importance of knowledge for students

10. The textbook raises students' interest in further English

language study.

b. Teaching Aids

1. The textbook book is supported efficiently by audiomaterials.

2. There is an available teacher's guide to aid the teacher.

3. Workbook is available to give useful guidance.

4. Cassettes that accompany the book are available.

5. The pictures and diagrams required to be brought by students are available for them.

6. The aids used help to build students' confidence.

7. Students are encouraged to bring real objects in class to illustrate some points of learning.

8. The posters and flash cards that accompany the book are available and suitable.

c. Teaching Methods

1. The teaching methods used in the book are the latest in the field.

2. The methods used are student-centered.

3. The activities allow students to talk more than teachers.

4. The activities used allow various class activities.

5. The activities used enable the learners to use English outside the classroom situation.

6. The activities can be exploited fully to acquire different language skills.

7. Activities can work well with methodologies in ELT.

8. The textbook encourages inductive approach to learning.

9. The textbook helps teachers exploit the activities to meet the students' expectations.

10. Activities and exercises introduce the main principles of CLT.

11. The textbook helps teachers cater for mixed- ability students and classes of different sizes.

12. The textbook includes lessons that reflect on study techniques.

13. Students are encouraged to take some degree of responsibility for their learning.

14. The textbook provides opportunity for teachers and students to localize activities.

3. Learning-teaching content

A. Subject and content

1. The material is up-to-date.

2. It covers a variety of topics from different fields.

3. The textbook contains fun elements

4. The language in the textbook is natural and real

5. The subject and content of the textbook is interesting,

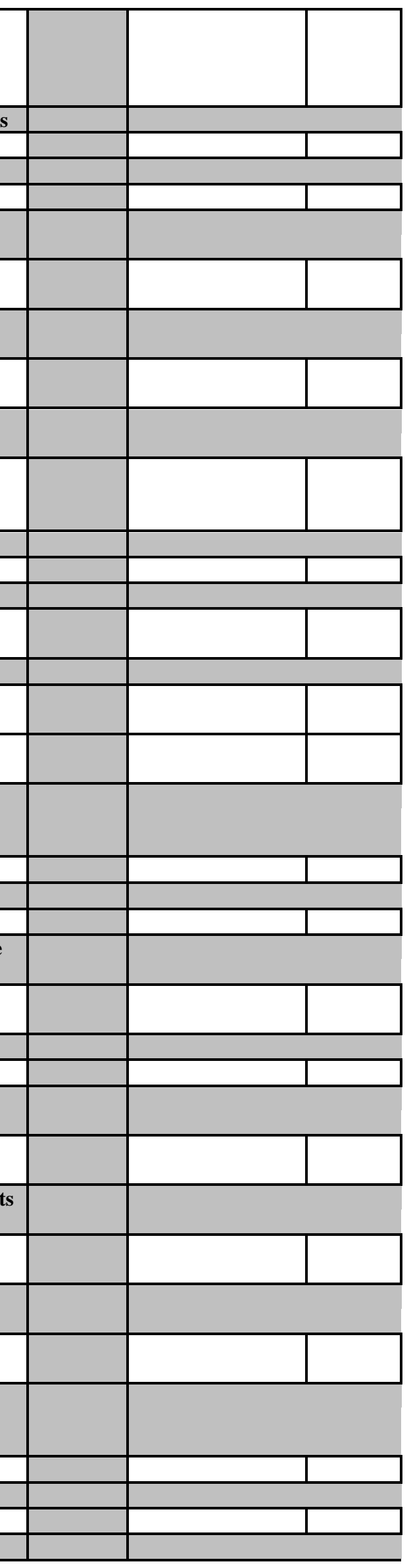


challenging and motivating.

6. The topics encourage students to express their own views

7. The topics allow students to think critically.

8. The course components are effectively and clearly organized around specific topics

9. The topics provide a list of new or difficult words.

B. Exercises

1. The exercises have clear instructions that explain how every exercise can be done.

2. The exercises are adequate, purposeful and interesting

3. The exercises foster the spirit of independent learning.

4. The textbook provides a balance of activities and tasks that

focus on both fluent and accurate production.

5. The exercises Tasks move from simple to complex.

6. The grammar points and vocabulary items are introduced in motivating and realistic contexts.

7. The exercises incorporate individual pair and group work.

8. The textbook's exercises can be modified or supplemented easily.

9. The textbook provides a variety of meaningful and mechanical exercises and activities to practice language items and skills.

10. The textbook provides models for final achievement tests.

C- Social and Cultural Contexts

1 The social and cultural contexts in the textbook are comprehensible

2 The content of the textbook is free from stereotypical images and information.

3 The textbook expresses positive views of ethnic origins, occupations, age groups and social groups.

4. The content presents different cultures.

5. The content discusses some well -known characters from different areas of the world.

6. The content helps students be aware of how to interact using the language within a new culture that is often very different from their own. .

7. The content displays different traditions and customs.

8. The three Ps of culture are represented in the content.

9. The topics of the content cope with the criteria of the students' culture.

4. Language Skills

A. Listening

1. The textbook has appropriate listening tasks with welldefined goals.

2. The listening passages help students develop their listening comprehension skills.

3. The cassettes expose the students to the voices and pronunciation of the native speakers of English

4. Listening material is well recorded, as authentic as possible.

5. Tasks are efficiently graded according to complexity from literary, inferential to critical listening skills.

6. Listening material is accompanied by background information, questions and activities.

7. The listening exercises focus on linguistic competence such as stress, intonation and form.

B. Speaking

1. Activities are developed to encourage student-student and student-teacher oral communication.

2. Activities are balanced between individual response, pair work and group work. 
3. Activities help students become a more confident English speaker

4. Speech exercises invite students to talk about their concerns and interests.

5. The situations in the dialogues sound natural .

6. There is sufficient material for spoken English (e.g. dialogues, role-plays, etc.) that help to de-emphasize teacher's talk.

C. Reading

1. There is sufficient reading material. (There is a range of varied and interesting reading text that can engage students cognitively and effectively.)

2. The content helps students develop reading comprehension skills.

3. Many of the reading passages are up-to-date, interesting and meaningful

4. Some reading passages are easy for most of the students to deal with.

5. The Length of the reading texts is appropriate.

6. The textbook uses authentic (real world) reading material at an appropriate level.

D. Writing

1. Tasks have achievable goals and take into consideration learners' capabilities.

2. Writing Tasks are interesting.

3. The writing tasks enhances free writing opportunities.

4. The time allotted for teaching the material is sufficient.

5. Some writings are easy for most of the students to deal with.

6. writings in the textbook are guided and controlled.

7. The textbook leads students from simple controlled writing activities to guided writing activities.

8. Writing activities are suitable in terms of length, degree of accuracy, and amount of guidance.

E. Vocabulary

1. The load (number of new words in each lesson) is appropriate to the linguistic level of students.

2. There is a good distribution (simple to complex) of vocabulary load across the whole book.

3. The exercises for vocabulary are rich and adequate.

4. Words are contextualized.

5. The topical nature of the vocabulary exercises is often meaningful to the students.

6. New lexical items appear in each unit.

7. There is specific method to teach new vocabulary.

8. The sentences and examples use words that are known by learners.

9. There is a list of vocabulary items tagged at the end of the textbook.

10. The content involves culture-specific items.

11. Words are accompanied with their phonetic transcription in English

G. Grammar

1. The grammar is contextualized.

2. The grammar examples are interesting and appropriate to the students' level.

3. Grammar is introduced explicitly.

4. The exercises for grammar practice are rich and adequate.

5. Structures are designed to be taught inductively.

6. Grammar lessons are often derived from the listening or reading passages.

7. The time allotted for teaching the material is sufficient. 8. Grammatical structures of statements are easy to be

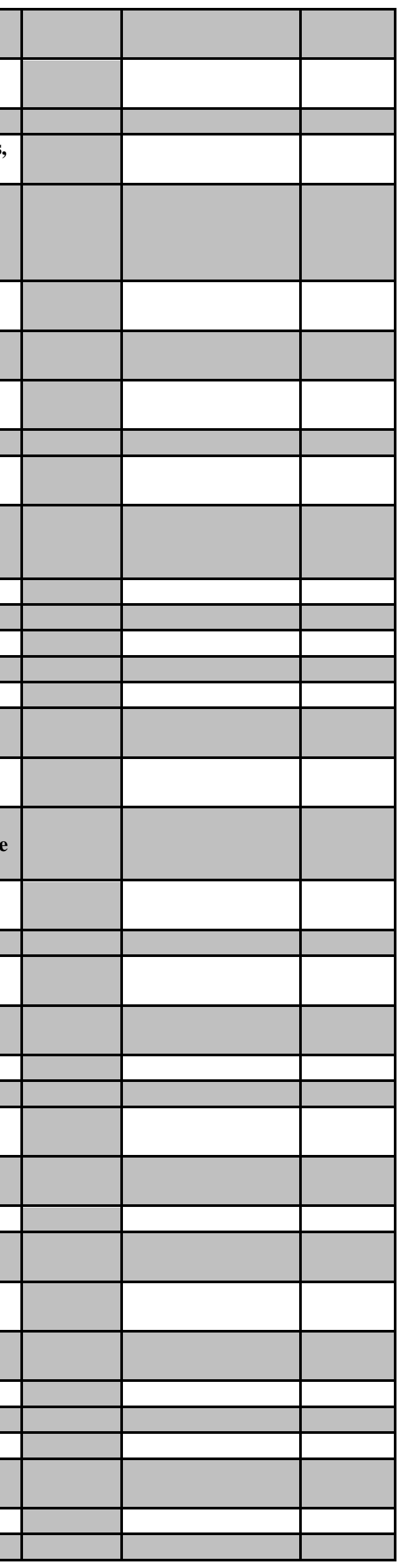


understood.

9. There is a balance between form and use.

10. The textbook covers the main grammar items appropriate to students at this grade.

11. The grammar points are presented with brief and easy examples and explanations.

H. Pronunciation

1. It is easy to be learnt.

2. Pronunciation is built through other types of activities, such

as listening, dialogue, etc.

3. There are cassettes/CDs for pronunciation practice.

4. The textbook highlights and practices natural pronunciation

(that is, stress and intonation).

5. The textbook includes adequate material for pronunciation

work.

\begin{tabular}{|l|l|l|l|}
\hline & & & \\
\hline & & & \\
\hline & & & \\
\hline ate to & & & \\
\hline & & & \\
\hline
\end{tabular}

